\title{
Study of cost effective and stay wise use of beds in a general hospital
}

\author{
Shashin Khadkekar ${ }^{1 *}$, Atish Gujrathi ${ }^{2}$, Sudha Karadkhedkar ${ }^{3}$
}

$\left\{{ }^{1}\right.$ Consultant ENT Surgeon, ${ }^{2}$ Assosiate Professor, Department of ENT $\}$ \{ ${ }^{3}$ Professor, Department of Physiology\} Dr. Shankarrao Chavan Govt. Medical College, Vishnupuri Nanded, Maharashtra, INDIA.

Email: $\underline{\text { drshashinkhadkekar@gmail.com }}$

Abstract Background: Health care facilities have improved greatly which has increase life expectancy of humans. Mostly the cost of treatment of ENT surgical patients depends upon duration of hospitalization. Otorhinolaryngology is well suited for shorter stay and most of the surgical procedures are elective. Material and Methods: In 20 beded unit we studied cost effectiveness of beds devoted for 3 day hospitalization which were admitted in five day beds. Results: Amongst all planned admissions in five day beds $69 \%$ patients were discharged within 3 days and cost effectiveness is studied. With this we found that remaining five day beds will be available for other patients. Conclusion: From this study it is proved that with this method of discharging patient on 3rd day admitted in five day beds, we can treat large no of patients without increasing the number of hospital beds.

Key Words: Five day beds, Hospital stay, cost effectiveness.

\section{*Address for Correspondence:}

Dr Shashin Khadkekar, Cons. Ent Surgeon, Department of ENT, Dr. Shankarrao Chavan Govt. Medical College, Vishnupuri Nanded

Khadkekar ENT Hospital Nanded, , Maharashtra, INDIA.

Email: drshashinkhadkekar@gmail.com

Received Date: 02/11/2019 Revised Date: 17/12/2019 Accepted Date: 12/01/2020

DOI: https://doi.org/10.26611/10161532

This work is licensed under a Creative Commons Attribution-NonCommercial 4.0 International License. $(\boldsymbol{C c})$ EY-NC

\begin{tabular}{|l|l|}
\hline \multicolumn{2}{|c|}{ Access this article online } \\
\hline Quick Response Code: & Website: \\
\hline & www.medpulse.in \\
\cline { 2 - 2 } & \\
\cline { 2 - 2 } & \\
\end{tabular}

\section{INTRODUCTION}

Health care is focused upon improving the quality and efficiency of health care services. As health care expenditure has been increasing it is essential for the public health sector to use existing resources efficiently through improving and controlling the hospital management ${ }^{1}$. Despite the level of resources devoted to hospital and health sector, there is increasing gap between available and required resources because health needs of developing countries have not diminished although they may have shifted with social, demographic and epidemiological changes. In developing countries the concern about high cost of health care in the light of scaree national and government resources has resulted in the close examination of hospital sector of health system ${ }^{2}$ Change is constant in health care environment and focus on improvements is essential. Any attempt to increase the hospital efficiency should begin at the point of care. Continuously adopting your hospital processes to meet the needs of your patients and workers will help to promote better quality of life for all. In surgical field day by day the focus is on reducing the hospital stay. Improvements and constant, continuous updating in anesthesia and surgical techniques made post-operative recovery faster. The benefits of reduced hospital stay are well known. ${ }^{3,4}$ Short stay unit are alternative to discharging or fully admitting emergency patients allowing extended patient observation. Emergency Units are primarily designed for short term acute care needs requiring long term care. Admitting patients to hospital unit is one of the most expensive routine decisions made in healthcare ${ }^{5}$. Otorhinolaryngology is well suited for shorter stay surgery. Many ENT procedures can be performed on day care basis while most others require short hospital stay. Though hospital duration of stay and hospitalization rates have reduced rapidly in past decade as more stress is given on short stay surgery. Specific modifications should be done and adopted for geriatric 
patients. Majority of ENT work is now undertaken in dedicated day care unit, the remaining are managed as inpatients ${ }^{6}$. The study is important as India needs to employ technology to come up with innovative, affordable healthcare for the poor and urban and rural areas. The present study examines the duration of hospitalization of our patients over 6 month period and assesses the role of five day beds in our unit.

\section{METHODS}

The ENT unit has 20 beded ward with 14 seven day beds and 6 five day beds. Patients requiring elective surgery expected to stay for 3 day or fewer are allotted a five day bed while reminder is admitted to seven day beds. The study is carried out in a period of 6 month from Jun 2019 to No 2019. Patients are divided in to two groups. First group whose admissions were planned and the second group are emergency admissions. Patient's age, diagnosis, treatment procedure, complications and duration of stay were noted. In this study we have concentrated on duration of hospital stay. Patients who were discharged on the same day were counted as staying for 1 day. As the beds were occupied for the remaining patients the day of discharge was not included in the duration of Hospitalization. The number of beds days per patient episode were then calculated and categorized into three groups according to duration of stay Hospital stay is calculated by this formula. ${ }^{7}$

\section{No. of Bed days \\ No.of days in month}

OBSERVATIONS

Table 1: Number of discharges for elective and planned admissions by month.

\begin{tabular}{ccccc}
\hline \multirow{2}{*}{ Month/Year } & \multicolumn{3}{c}{ Duration of Stay } & \\
\cline { 2 - 4 } & $<3$ & $\begin{array}{c}4-5 \\
\text { days }\end{array}$ & $\begin{array}{c}>6 \\
\text { days }\end{array}$ & days \\
& 51 & 5 & 17 & 73 \\
\hline Jun 2019 & 53 & 9 & 14 & 76 \\
July & 32 & 4 & 10 & 46 \\
Aug & 50 & 5 & 17 & 72 \\
Sept & 51 & 16 & 7 & 74 \\
Oct & 52 & 14 & 9 & 75 \\
Nov & 289 & 53 & 74 & 416 \\
Total & & & & \\
\hline
\end{tabular}

\begin{tabular}{cc} 
Table 2: Procedures performed in 6- month period \\
\hline Procedure & $\begin{array}{c}\text { No. of } \\
\text { Patients }\end{array}$ \\
\hline Tympanoplasty & 51 \\
Mastoidectomy & 76 \\
Myringotomy with Gromet & 26 \\
Tonsillectomy - Adenoid & 65 \\
Septoplasty / SMR & 36 \\
Endonasal DCR & 20 \\
Endoscopic Sinus Surgery & 56 \\
Bronchoscopy & 05 \\
Submandi gland excision & 10 \\
\hline
\end{tabular}

\begin{tabular}{cc}
\hline Parotidectomy & 13 \\
Hemithyroidectomy & 16 \\
Tracheostomy & 10 \\
Oesophagoscopy & 05 \\
Fracture \# Nasal bone & 04 \\
Reduction & \\
Peritonsillar abscess & 03 \\
Microlaryngeal surgery & 20 \\
\hline Total & 416 \\
\hline
\end{tabular}

Table 3: Number of elective bed days per month separated

\begin{tabular}{ccccc}
\multicolumn{5}{c}{ according to three durations of stay } \\
\hline Month/Year & $\begin{array}{c}<3 \\
\text { days }\end{array}$ & $\begin{array}{c}4-5 \\
\text { days }\end{array}$ & $\begin{array}{c}>6 \\
\text { days }\end{array}$ & $\begin{array}{c}\text { No. of } \\
\text { beds }\end{array}$ \\
\hline June 2019 & 90 & 33 & 117 & $5.0(5)$ \\
July & 85 & 62 & 139 & $6.4(6)$ \\
Aug & 79 & 49 & 120 & $5.6(6)$ \\
Sept & 102 & 3 & 110 & $4.7(5)$ \\
Oct & 80 & 55 & 107 & $5.2(5)$ \\
Nov & 83 & 63 & 88 & $5.3(5)$
\end{tabular}

Calculated from patients staying 4 days or more no. of seven day beds $\frac{\text { No.of Bed days }}{\text { No.of days in month }}$

Table 4: Number of emergency admission and No. of bed days per month as per three types of duration of stay

\begin{tabular}{|c|c|c|c|c|c|}
\hline \multirow{2}{*}{ Month } & \multirow{2}{*}{$\begin{array}{c}\text { No. of } \\
\text { Admissions }\end{array}$} & \multicolumn{3}{|c|}{ No of bed days } & \multirow[t]{2}{*}{$\begin{array}{c}\begin{array}{c}\text { No. of } \\
\text { beds }\end{array} \\
\end{array}$} \\
\hline & & $\begin{array}{l}<3 \\
\text { days }\end{array}$ & $\begin{array}{c}4-5 \\
\text { days }\end{array}$ & $\begin{array}{c}>6 \\
\text { days }\end{array}$ & \\
\hline $\begin{array}{l}\text { June } \\
2019\end{array}$ & 48 & 32 & 45 & 124 & $6.7(7)$ \\
\hline July & 42 & 30 & 31 & 121 & $5.8(6)$ \\
\hline Aug & 47 & 26 & 50 & 119 & $6.5(7)$ \\
\hline Sept & 49 & 29 & 55 & 127 & $7.03(7)$ \\
\hline Oct & 40 & 25 & 22 & 105 & $4.9(5)$ \\
\hline Nov & 42 & 31 & 40 & 98 & $5.6(6)$ \\
\hline Total & 268 & 173 & 243 & 694 & \\
\hline
\end{tabular}

\section{RESULTS}

In our study, total 694 patients were admitted and discharged during 6 month period. Out of these 416 patients were admitted for elective procedures. Remaining 268 were emergencies.

Table No.1 shows the number of discharges per month for elective admissions as per the duration of stay, out of 416 elective admissions, 289 (69\%) were discharged within 3 days. Remaining 53(12\%) patients stayed for 4-5 days.

Table No.2 shows procedures performed during this study period.

Table No.3 and 4 shows number of bed days by month for elective and emergency admissions. Those patients who stayed for 4 or more days needed a seven day bed. Number of seven day beds required for these elective admissions would vary from 5.03 to 6.4 with a mean of 5.3 beds (Table No.3). Table No.4 shows total number of 
emergency admissions. The number seven day beds required to accommodate these patients varies from 4.9 to 7.03 with a mean of 5.9 beds per day. Considering the maximum no. of beds required, we should not need more than 14 ( 7 elective plus 7 emergency) Seven day beds, thus saving almost 6 beds.

\section{DISCUSSION}

In health care systems hospitals provide primary care, serve as referral hospitals for higher level care. However, hospitals require more human and financial resources than any other institution in the sector. In both developed and developing countries hospitals are viewed as vital and necessary community resources that should be managed effectively for the benefit of community ${ }^{2}$. Duration of hospital stay plays important role in determining the cost of treatment. By reducing unnecessary hospital stay we can increase the efficiency of our beds either by increasing resources or reducing the bed requirement. Both results in lowered cost per patient treated ${ }^{8,} 9$. In our study we have 20 beds for ENT unit. Out of these 14 were allotted as seven day beds and 6 were allotted as five day beds. Total 694 patients were admitted during 6 months study period, out of 416 elective, planned admissions 289 $(69 \%)$ were discharged within 3 days, remaining 53 (12\%) patients stayed for 4-5 days. As majority (69\%) patients were discharged within 3 days, remaining 6 seven day beds were utilized for next inflow of patients. Thus we could treat more number of patients with minimum resources. Our study proves that short stay surgery improves the quality of patient care while reducing the hospital stay. Enhanced recovery was based on established day care surgery principles and was aimed at improving quality of recovery after in patient's surgery 10,11. From our study it is clear that short stay of patients could reduce the risk of hospital acquired infections, increased patient satisfaction and yield more efficient use of hospital beds. ME zonderland, RJ Boucherie et al. in their study stated that short stay will increase the admission rates at the expense of decrease in number of elective admissions. ${ }^{12} \mathrm{C}$ storm, JS Stefansson et al. in their study assessed beneficial and harmful effects of short stay unit hospitalization compared with usual care in people with internal medicine diseases and conditions. They also observed that short stay might reduce hospital admission rate, hospital duration, hospital re admission and the expenditure without compromising the quality of patient care. ${ }^{13}$ Another benefit of short stay surgery is hospital doesn't require additional personnel or hospital beds allowing rational use of limited resources coupled with measurable benefits for the patients ${ }^{14}$. Our study also proved to be helpful in estimating the expected patient stay, spacing the number of admissions to fit with projected number of beds. Further reduced use of hospital beds and optimization of turnover rate of hospital staffs could minimize economic losses and reduced hospital costs and waste of personnel times. Short stay surgery planning involves surgical aspects, nursing and paramedical services. Community nurses and family members will have more responsibility after immediate post-operative phase and after discharge from the hospital ${ }^{11}$. Findings of this study are useful for institutional, managerial and clinical decision makers regarding implementation of short surgery unit in a hospital setting and better management. ${ }^{15}$

\section{CONCLUSION}

Our study findings show some potential benefits of short hospital stay and support implementation of this at organizational level in hospital settings. Further study should focus on criteria for identifying patients for short hospital study admissions. Findings of the study may be useful in planning effective approaches to management of resources, patient care management, and administrative systems for efficient optimum use. Considering the maximum benefit to patients and staff, findings of this study are also useful in increasing the efficiency and effectiveness in day-to-day running of small set up short stay surgical units.

\section{REFERENCE}

1. Minth HV, Giang KB, Huong LH, NT etal (2010) costing of clinical services in rural district hospitals in Northen Vietnam. Int.J.Health Plan M25:63-73.

2. Newbrander W, Barnum H, Kutzinj (1992) Hospital economics and financing in developing countries. Geneva world health organization.

3. Myfawny M, beech R Variations in length of stay and rates of day care surgery - Implications For efficiency of surgical management J.Rpid and Comm Health 1990; 44:90-105.

4. Schimmel Om, The hazards of hospitalization Ann.Int. Med.1964; 60:100-10

5. J Chavis, AL Cochran, KE Kocher-2016 https://dl.org pages1982-1993. Simulation model of patientf low through the emergency department to determine the impact of short stay unit on hospital congestion.

6. Med J. Armed forces India 2009 Jan, 60(1):31-34 VP singh and SP Karla, Avsm Bar.

7. JR CollSurg of Edinb-40 1995: 46-48 KenerthKoh

8. Litwn MS, Mahn KL, Resecius N Why do sicker patients cost more? A charged based analysis of patients Jr.Urol. $1993: 14984-8$

9. Clinical Otolaryngol 2009 Jun, 34 (3): 259-60 Carr, FR, etal - Multidiscriplinary audit of clinical coding accuracy in otolaryngology: financial, managerial and clinical governance considerations under payments by results.

10. Ball L.B. Manday to Friday : Short Surgical unit Nursing Management 1986, 17: 42J-42L 
11. Liewellyn. J.G. Short stay surgery present practices and future trends AORN J. 1991; 53: 1179-9

12. ME Zonderland, RJ Boucherie, MW Carter. Modelling the effect of short stay units on patient admissionsOperations Research for healthcare 2015 21-27.

13. C.Storm, JS stafansson, ML fabritus. Hospitalization in short stay units for adults with internal Medicine diseases and conditions. Cochrane Database Syst.Rev.2018 Aug.13; 8(8) CDO12370.
14. Guiro, Martinz R, somepereselva MT et.al Short stay medical unit- an alternative to conventional Hospoitalization revista clinica Espanola, 2008, 208(5): 216-21.

15. Downing H, Scott C, Kelly C. Evaluation of dedicated short stay unit for Acute Medical Admission Clinical Medicine $\quad 2008 ; \quad 8(i)$ : $\quad 18-20$

Source of Support: None Declared
Conflict of Interest: None Declared

\section{Policy for Articles with Open Access:}

Authors who publish with MedPulse International Journal of ENT (Print ISSN: 2579-0854) (Online ISSN: 2636-4727) agree to the following terms: Authors retain copyright and grant the journal right of first publication with the work simultaneously licensed under a Creative Commons Attribution License that allows others to share the work with an acknowledgement of the work's authorship and initial publication in this journal.

Authors are permitted and encouraged to post links to their work online (e.g., in institutional repositories or on their website) prior to and during the submission process, as it can lead to productive exchanges, as well as earlier and greater citation of published work. 